\title{
Delivery outcomes in women with congenital heart disease: results from the Cuban National Programme for pregnancy and heart disease
}

\author{
Cristina Munte Kinsella', Sara A. Thorne ${ }^{2}$, Hsu Chong ${ }^{1,3^{*}}$, Paul F. Clift ${ }^{1,2}$, Roman Vasallo Peraza ${ }^{4}$,
} Jesus E. Perez Torga ${ }^{4}$ and Pedro A. Roman Rubio ${ }^{4}$

\begin{abstract}
Objective: To inform on delivery outcomes achieved in congenital heart disease (CHD) patients by the Cuban National Programme for pregnancy and heart disease.

Methods: Single-centre retrospective study on a prospectively collected cardiac pregnancy database at a tertiary referral hospital (January 2000-May 2017). Primary outcomes: pregnancy duration, outcome, maternal/fetal complications.

Results: Four hundred sixty-seven pregnancies in 462 recorded cases reached third trimester. Median age: 25 (21-29) years. Patients presented in NYHA class I $(97 \%, n=453)$ or $I I(3 \%, n=14), 6 \%(n=27)$ had arrhythmias, $1 \%(n=4)$ had co-morbidities, $1 \%(n=4)$ had impaired left ventricular function. There were 464 singleton pregnancies and 3 twin pregnancies. Of the singleton pregnancies, one resulted in stillbirth (0.2\%). The rest were live births $(n=463)$, median weight 3200 (2900-3421) grams. Median pregnancy duration: 39.1 (38.6-40) weeks. Caesarean rate: 34\% ( $n=156)$. All twin pregnancies $(n=3)$ resulted in live births $(n=6)$ via caesarean section, of median weight $2710(2458-2850)$ grams and median pregnancy duration 37 (36-38) weeks. Maternal cardiovascular complications $(<0.5 \%, n=2)$, and obstetric complications $(14 \%, n=67)$ did not result in any mortality. Small-for-gestational-age was the commonest neonatal complication (10\%, $n=48)$, with zero mortality. Three neonates (1\%) had CHD. Post-delivery maternal NYHA functional status: class I in $84 \%(n=393)$, class II in $16 \%(n=73)$, and class III in one patient $(<0.5 \%)$.
\end{abstract}

Conclusion: In middle-income countries management of $\mathrm{CHD}$ pregnancies according to existing guidelines can achieve good maternal and fetal outcomes.

Keywords: Congenital heart disease, Pregnancy, Delivery outcomes, Cuba

\section{Introduction}

Due to developments in cardiac surgery and congenital cardiology, women with congenital heart disease (CHD) are now consistently reaching adulthood [1]. CHD has since become one of the most common types of heart disease in pregnancy [2], and represents a significant cause of morbidity to the gravid patient, as well as a risk

\footnotetext{
* Correspondence: H.P.Chong@bham.ac.uk

${ }^{1}$ Institute of Cardiovascular Sciences, Birmingham B15 2TT, UK

${ }^{3}$ Birmingham Women's Hospital, Academic Unit, 3rd Floor, Metchley Park

Road, Birmingham B15 2TG, UK

Full list of author information is available at the end of the article
}

of mortality [3, 4]. In the developed world, high-risk pregnant $\mathrm{CHD}$ patients should have access to tertiary Adult Congenital Heart Disease (ACHD) centres $[5,6]$. Conversely, little is known about pregnancy outcomes for women in low and middle-income countries [3]. This article seeks to address this gap in the literature, examining and updating the delivery outcomes achieved in CHD patients managed by the Cuban National Programme for pregnancy and heart disease $[7,8]$.

(C) The Author(s). 2019 Open Access This article is distributed under the terms of the Creative Commons Attribution 4.0 International License (http://creativecommons.org/licenses/by/4.0/), which permits unrestricted use, distribution, and reproduction in any medium, provided you give appropriate credit to the original author(s) and the source, provide a link to the Creative Commons license, and indicate if changes were made. The Creative Commons Public Domain Dedication waiver (http://creativecommons.org/publicdomain/zero/1.0/) applies to the data made available in this article, unless otherwise stated. 
Complications in CHD pregnancies and risk assessment Complications arising from a CHD pregnancy can be broadly divided into three main categories: maternal cardiac complications, obstetric complications and fetal complications. Studies have estimated the incidence of cardiac complications at 10-13\% in the CHD population [9-11]. Amongst these, heart failure and arrhythmias were identified as the most common [12]. In terms of obstetric complications, CHD pregnancies are associated with a higher rate of thromboembolism than in the general population (1:50 vs 1:1000-2000) [11]. Whilst overall rates of pregnancy-related hypertensive disorders are broadly similar to that of the healthy population $(8.7 \%$ vs $8 \%$ ), the incidence of pre-eclampsia and pregnancy induced hypertension can vary widely depending on the specific CHD examined. Lastly, it is estimated that $30 \%$ of fetuses experience complications [13], and women with CHD are more likely to have a spontaneous miscarriage or therapeutic abortion [14]. Further complications include an increased risk of premature birth above background, growth restriction and stillbirth [4, 9, 15-17], perhaps going some way in explaining why fetal mortality rates are four times higher in CHD pregnancies [13]. Overall, maternal mortality is not particularly high for most types of $\mathrm{CHD}$, however rates of morbidity remain much higher in CHD patients and their offspring than in the general population [2].

Because of the high risk of complications in pregnancy and delivery, the importance of preconception counselling and appropriate risk stratification cannot be overstated. Preconception counselling should begin in adolescence, and should take place in a tertiary centre experienced in both the care of ACHD patients and high-risk pregnancies. Advice provided varies on a case-by-case basis, but should generally include guidance on appropriate contraception methods, a medication review and an appropriate assessment of the maternal cardiovascular risk that would be sustained in pregnancy $[5,6]$. Three risk calculators have been validated to provide reliable information in this regard: the modified World Health Organisation (mWHO) classification of pregnancy risk [18], the CARPREG risk score [9] and the ZAHARA risk score [4]. Of these, the most effective is the mWHO classification of pregnancy risk, which is based primarily on the type and severity of the maternal heart defect [10].

\section{The management of delivery in CHD patients}

Guidelines on the management of delivery in CHD pregnancies have become more widely available in recent years. Pregnant women considered high-risk (mWHO class III-IV) should always give birth in a tertiary care centre where an appropriate multi-disciplinary team (MDT) can be called upon [5, 6]. Members of the MDT will usually include an experienced obstetrician, a cardiologist, a neonatologist and an anaesthetist [19]. Spontaneous vaginal delivery is considered the preferred option for most CHD patients. Exceptions to this include an obstetric indication and/or a small number of high-risk cardiac conditions, where the Valsalva manoeuvre during active second stage may cause potentially detrimental haemodynamic changes $[6,19]$. Indications for caesarean section (CS) include patients on oral anticoagulants going into preterm labour, Marfan's syndrome and other aortopathies with a fragile aorta, and the presence of acute intractable heart failure [6]. However, most guidance in this regard lacks definitive evidence, and relies instead on expert opinion.

\section{Managing CHD pregnancies in low and middle-income countries}

CHD expertise can be much more difficult to access in low and middle-income countries. In Latin America, exceptions to this rule are found in Mexico, Brazil and Cuba, where contrary to the norm, such care is available to the population [20-22]. The Cuban National Programme for heart disease in pregnancy remains the most established of these, having been in existence for close to 20 years.

It operates under the umbrella of the Institute of Cardiology and Cardiovascular Surgery in Havana, and has its base at the Hospital of Obstetrics and Gynaecology "Ramon Gonzalez Coro", also based in Havana. As a national service, patients are referred via regional coordinators, and are assessed by the team of two consultant cardiologists and an obstetrician working for the Programme. Those deemed of sufficiently high-risk ( $\mathrm{mWHO}$ criteria class II-III, III and IV) [18] are managed by the team for the duration of their pregnancy. Patients with pregnancies deemed class I and II are referred back to their regional hospital, with remote support available from the team where necessary. Pregnancies managed by the team in Havana are reviewed at 20-22 weeks, at 28-29 weeks, 34 weeks and at term. A cardiovascular management plan for delivery is made for each patient; following birth mothers remain under observation for at least 5 days. Post-discharge, they attend a follow-up appointment with a member of the team within 6 weeks.

However, even within established services such as the Cuban Programme, care provided can differ from that offered in high-income countries. A scarcity of resources and expertise, as well as long travel distances to access services and cultural, socioeconomic and ethnic differences in the populations served can all influence healthcare outcomes for the CHD patient. Hence, there is a need to update and clarify the outcomes achieved for these patients in these services; the following analysis seeks to provide some such clarity. 


\section{Materials and methods}

\section{Study design and patient population}

This was a retrospective single-centre study conducted on a prospectively collected cardiac pregnancy database at a tertiary referral hospital. The research protocol was approved by the local Institutional Review Board. Verbal informed consent was obtained for all participants in the study; written informed consent was not deemed necessary by the Review Board. The database comprised data from 1st January 2000 to 15th May 2017, and included a record of patients admitted under the Programme at its base in the Hospital of Obstetrics and Gynaecology "Ramon Gonzalez Coro" over this period. Data were collected on discharge using both obstetric and medical records, and anonymised at the point of collection, hence it was not usually possible to identify patients who presented to the Service in subsequent pregnancies.

Baseline data collected included: demographics (age, province of origin), CHD diagnosis/diagnoses, presence of significant co-morbidities, New York Heart Association (NYHA) functional status class I-IV prior to pregnancy, and baseline ECG and echocardiography results.

\section{Study outcomes and follow-up assessment}

The primary data outcomes recorded were: duration of pregnancy, outcome of pregnancy and any maternal or fetal complications experienced. Additional labour outcomes recorded included: mode of delivery, indication for caesarean section, birthweight, gestational age at delivery, fetal gender and the use of oxytocin in induction or augmentation of labour (data on the use of tocolytics in the third stage of labour were not collected). Small-for-gestational-age was defined as a baby born with a birth weight less than the 10th centile. Intrauterine growth restriction was defined as an estimated fetal weight less than the 10th centile based on ultrasound based centiles calculated using Hadlock's formula. Maternal complications data were further classified into cardiovascular and obstetric. Following delivery, further maternal outcomes recorded included: post-partum NYHA functional class, heart failure, resting oxygen saturations (if abnormal: <92\%), arrhythmias requiring a permanent pacemaker.

\section{Results}

A total of 501 cases were identified. Of these, 487 had follow-up outcomes available at the time of analysis, and so were included in the study. Of the 487 cases, 7 (1.4\%) were a repeat pregnancy, bringing the total number of recorded pregnancies analysed to 495 . Out of 495 pregnancies, 27 (5\%) were terminated on or before 22 weeks gestation, with one $(0.2 \%)$ additional pregnancy terminated at 26 weeks. Overall, 467 pregnancies were further evaluated. Pregnancies from women who had more than one pregnancy, were treated independently.

The baseline characteristics of the 467 CHD pregnancies managed at the Hospital "Ramon Gonzalez Coro" are described in Table 1. Overall, the median age at pregnancy was 25 (21-29) years. While all Cuban provinces were represented in the study population, most of the cases originated from Havana (71\%). Patients had a wide variety of congenital heart defects (Table 1). Six cases involved a mWHO IV classed cardiac lesion, where pregnancy is contraindicated [18]. All cases presented in NYHA class I $(97 \%, n=453)$ or II $(3 \%, n=14), 6 \%(n=27)$ had arrhythmias, $1 \%(n=4)$ reported a significant co-morbidity, and $1 \%(n=4)$ had impaired systemic ventricular function.

There were 464 singleton pregnancies and 3 twin pregnancies (Table 2). Of the singleton pregnancies, one pregnancy resulted in stillbirth $(0.2 \%)$, with the rest resulting in live births $(99.8 \%, n=463)$, at a median duration of gestation of 39.1 (38.6-40) weeks and a median birth weight of 3200 (2900-3421) grams. Sixty-seven percent of cases $(n=308)$ resulted in a vaginal delivery, with caesarean section rates of $34 \%(n=156)$. Oxytocin was used in 98 (21\%) deliveries before the third stage. In 77 deliveries (79\%) this was for induction, and in 21 cases $(21 \%)$ this was for augmentation. Indications for caesarean delivery were divided into cardiovascular indications and obstetric indications. Cardiovascular indications existed in $19 \%$ of cases $(n=30)$. All six women with $\mathrm{mWHO}$ class IV disease were delivered by caesarean section: five were for cardiac reasons and one was performed for obstetric reasons at 41 weeks gestation. Only one of the five women with WHO Class IV disease was delivered preterm ( 32 weeks gestation), and this was for cardiac reasons. All twin pregnancies $(n=3)$ resulted in live births $(n=6)$, at a median duration of gestation of 37 (36-38) weeks, and a median birth weight of 2710 (2458-2850) grams. All twins were born via caesarean section.

Maternal cardiovascular complications did not result in mortality. One patient developed an arrhythmia, and a further one severe mitral insufficiency. The most prevalent maternal obstetric complication was gestational diabetes, which was present in $8 \%(n=36)$ of pregnancies. This was followed by gestational hypertension in $2 \%$ of pregnancies $(n=11)$, haemorrhage $(1 \%$, $n=4)$, and uterine atony $(1 \%, n=4)$. Additionally, there were reported cases of pre-eclampsia $(<0.5 \%, n=2)$, endometritis $(<0.5 \%, \mathrm{n}=2)$, sepsis $(<0.5 \%, \mathrm{n}=2)$, and uterine rupture $(<0.5 \%, \mathrm{n}=1)$.

Within the cohort of live births, being small-for-gestational-age was the commonest complication $(10 \%, n=48)$. Preterm birth affected $5 \%$ of pregnancies (23 singleton, 1 twin), and intrauterine growth restriction was noted in $3 \%$ of pregnancies (12 
Table 1 Baseline characteristics

\begin{tabular}{|c|c|}
\hline & $\begin{array}{l}\text { CHD pregnancies } \\
(n=467)\end{array}$ \\
\hline$\overline{\text { Age }(\text { years) }}{ }^{a}$ & $25(21-29)$ \\
\hline \multicolumn{2}{|l|}{ Province of origin, $n(\%)$} \\
\hline Pinar del Rio & $12(3)$ \\
\hline Artemisa & $28(6)$ \\
\hline Havana & $330(71)$ \\
\hline Mayabeque & $20(4)$ \\
\hline Matanzas & $15(3)$ \\
\hline Cienfuegos & $3(1)$ \\
\hline Villa Clara & $2(<0.5)$ \\
\hline Sancti Spiritus & $4(1)$ \\
\hline Ciego de Avila & $7(1)$ \\
\hline Camaguey & $8(2)$ \\
\hline Las Tunas & $6(1)$ \\
\hline Granma & $12(3)$ \\
\hline Holguin & $7(1)$ \\
\hline Santiago de Cuba & $3(1)$ \\
\hline Guantanamo & $6(1)$ \\
\hline Isla de la Juventud & $3(1)$ \\
\hline Other (Venezuela) & $1(<0.5)$ \\
\hline \multicolumn{2}{|l|}{ Diagnosis, n (\%) } \\
\hline mWHO I & $333(71)$ \\
\hline Atrial Septal Defect (ASD) - repaired & $33(7)$ \\
\hline Atrial Septal Defect (ASD) - unrepaired & $57(12)$ \\
\hline Atrioventricular Septal Defect (AVSD) - repaired & $3(1)$ \\
\hline $\begin{array}{l}\text { Atrioventricular Septal Defects (AVSD) } \\
\text { - unrepaired }\end{array}$ & $3(1)$ \\
\hline Bicuspid aortic valve & $5(1)$ \\
\hline Other & $29(6)$ \\
\hline Patent Ductus Arteriosus (PDA) - repaired & $7(1)$ \\
\hline Patent Ductus Arteriosus (PDA) - unrepaired & $17(4)$ \\
\hline Pulmonary stenosis - repaired & $11(2)$ \\
\hline $\begin{array}{l}\text { Pulmonary stenosis (mild-moderate) } \\
\text { - unrepaired }\end{array}$ & $52(11)$ \\
\hline Ventricular Septal Defect (VSD) - repaired & $3(1)$ \\
\hline Ventricular Septal Defect (VSD) - unrepaired & $113(24)$ \\
\hline mWHO ॥ & $81(17)$ \\
\hline Coarctation of the aorta - repaired & $26(6)$ \\
\hline $\begin{array}{l}\text { Coarctation of the aorta (mild-moderate) } \\
\text { - unrepaired }\end{array}$ & $14(3)$ \\
\hline Tetralogy of Fallot - repaired & $41(9)$ \\
\hline mWHO III & $47(10)$ \\
\hline Aortic stenosis & $2(<0.5)$ \\
\hline $\begin{array}{l}\text { Congenitally corrected Transposition of the } \\
\text { Great Arteries (CTGA) }\end{array}$ & $2(<0.5)$ \\
\hline Ebstein's anomaly & $14(3)$ \\
\hline
\end{tabular}

Table 1 Baseline characteristics (Continued)

\begin{tabular}{|c|c|}
\hline & $\begin{array}{l}\text { CHD pregnancies } \\
(n=467)\end{array}$ \\
\hline Fontan & $3(1)$ \\
\hline $\begin{array}{l}\text { Pulmonary regurgitation (mild - moderate) } \\
\text { - unrepaired }\end{array}$ & $4(1)$ \\
\hline Pulmonary stenosis (severe) -unrepaired & $5(1)$ \\
\hline Sub-aortic stenosis - repaired & $3(1)$ \\
\hline Sub-aortic stenosis - unrepaired & $9(2)$ \\
\hline $\begin{array}{l}\text { Transposition of the Great Arteries (TGA) } \\
\text { - arterial switch }\end{array}$ & $5(1)$ \\
\hline $\mathrm{mWHO}$ IV & $6(1)$ \\
\hline Pulmonary Hypertension & $4(1)$ \\
\hline $\begin{array}{l}\text { Severe coarctation of the aorta } \\
\text { - unrepaired }\end{array}$ & $2(<0.5)$ \\
\hline \multicolumn{2}{|l|}{ Co-morbidities } \\
\hline Yes & $4(1)$ \\
\hline No & $463(99)$ \\
\hline \multicolumn{2}{|l|}{ Functional status at the start of pregnancy, n (\%) } \\
\hline । & $453(97)$ \\
\hline$\|$ & $14(3)$ \\
\hline III & $0(0)$ \\
\hline IV & $0(0)$ \\
\hline \multicolumn{2}{|l|}{ Arrhythmias, n (\%) } \\
\hline Yes & $27(6)$ \\
\hline No & $440(94)$ \\
\hline \multicolumn{2}{|l|}{ Left ventricular function, $\mathrm{n}(\%)$} \\
\hline Normal (> 55\%) & $463(99)$ \\
\hline Impaired (<55\%) & $4(1)$ \\
\hline
\end{tabular}

Baseline data collected on $467 \mathrm{CHD}$ pregnancies managed by the Programme 2000-2017. ${ }^{\mathrm{a}}$ Age was only available for 463 patients. Continuous data is presented as median (interquartile range)

singleton). Four women were delivered preterm due to concerns about cardiac function (three at 32 completed weeks and one at 34 completed weeks gestation), and all four women were delivered by caesaraean section.

Following delivery, 4 singleton babies had a low Apgar score (1\%) (three at term and one preterm). Further complications present in neonates included neonatal jaundice (1\%, 3 singleton babies), meconium aspiration syndrome $(<0.5 \%, 1$ singleton baby), hypoxia $(<0.5 \%, 1$ singleton baby), and respiratory depression $(<0.5 \%, 1$ singleton baby). Congenital malformations were found in 5 singleton babies (1\%). Three (1\%) had congenital cardiac defects (unrelated to the mother) and $2(<0.5 \%)$ had other congenital malformations. Following birth and up to 6 weeks of age, there were no reported neonatal deaths.

Post-natal maternal cardiovascular outcomes are summarised in Table 3. At 6 weeks follow-up, NYHA functional status was class I in $84 \%(n=393)$ of cases, 
Table 2 Pregnancy outcomes

\begin{tabular}{|c|c|c|}
\hline & $\begin{array}{l}\text { Singleton CHD } \\
\text { pregnancies }(n=464)\end{array}$ & $\begin{array}{l}\text { Twin CHD } \\
\text { pregnancies }(n=3)\end{array}$ \\
\hline $\begin{array}{l}\text { Duration of pregnancy } \\
\text { (weeks) }\end{array}$ & $39.1(38.6-40.0)$ & $37(36-38)$ \\
\hline \multicolumn{3}{|l|}{ Outcome of pregnancy } \\
\hline Live birth & $463(99)$ & $6(100)$ \\
\hline \multirow[t]{2}{*}{ Stillbirth } & $1(<1)$ & $0(0)$ \\
\hline & Live births $(n=463)$ & Live births $(n=6)$ \\
\hline Birth weight (gr) & $3200(2900-3421)^{a}$ & $2710(2458-2850)$ \\
\hline \multicolumn{3}{|l|}{ Mode of delivery, n (\%) } \\
\hline Vaginal & $308(66)$ & $0(0)$ \\
\hline Caesarean section & $156(34)$ & $6(100)$ \\
\hline \multicolumn{3}{|l|}{ Indications for caesarean, n (\%) } \\
\hline Cardiovascular indication & $30(19)$ & $0(0)$ \\
\hline Obstetric indication & $126(81)$ & $3(100)$ \\
\hline \multicolumn{3}{|c|}{ Maternal cardiovascular complications, n (\%) } \\
\hline Mitral insufficiency & $1(<0.5)$ & $0(0)$ \\
\hline Arrhythmia & $1(<0.5)$ & $0(0)$ \\
\hline \multicolumn{3}{|c|}{ Maternal obstetric complications, n (\%) } \\
\hline Gestational diabetes & $35(8)$ & $1(33)$ \\
\hline Gestational hypertension & $11(2)$ & $0(0)$ \\
\hline Pre-eclampsia & $2(<0.5)$ & $0(0)$ \\
\hline Thromboembolism & $0(0)$ & $0(0)$ \\
\hline Haemorrhage & $4(1)$ & $0(0)$ \\
\hline Haematoma & $2(<0.5)$ & $0(0)$ \\
\hline Endometritis & $2(<0.5)$ & $0(0)$ \\
\hline Uterine rupture & $1(<0.5)$ & $0(0)$ \\
\hline Uterine atony & $3(1)$ & $1(33)$ \\
\hline Sepsis & $2(<0.5)$ & $0(0)$ \\
\hline \multicolumn{3}{|l|}{ Neonatal complications } \\
\hline Acute fetal distress & $18(4)$ & $0(0)$ \\
\hline Preterm birth & $22(5)$ & $2(33)$ \\
\hline $\begin{array}{l}\text { Intrauterine growth } \\
\text { restriction }\end{array}$ & $12(3)$ & $0(0)$ \\
\hline Small for gestational age & $48(10)^{\mathrm{a}}$ & $0(0)$ \\
\hline Low Apgar score & $4(1)$ & $0(0)$ \\
\hline Hypoxia & $1(<0.5)$ & $0(0)$ \\
\hline Respiratory depression & $1(<0.5)$ & $0(0)$ \\
\hline $\begin{array}{l}\text { Meconium aspiration } \\
\text { syndrome }\end{array}$ & $1(<0.5)$ & $0(0)$ \\
\hline Neonatal jaundice & $3(1)$ & $0(0)$ \\
\hline $\begin{array}{l}\text { Congenital cardiac } \\
\text { defects }\end{array}$ & $3(1)$ & $0(0)$ \\
\hline Other fetal malformations & $2(<0.5)$ & $0(0)$ \\
\hline Post-natal mortality & $0(0)$ & $0(0)$ \\
\hline
\end{tabular}

Pregnancy outcomes for $467 \mathrm{CHD}$ pregnancies managed by the Programme 2000-2017. ${ }^{\mathrm{a}}$ Birth weight and consequently small-forgestational-age results were only available for 462 neonates. Continuous data is presented as median (interquartile range)
Table 3 Maternal cardiovascular outcomes at six-week followup

\begin{tabular}{ll}
\hline & $\begin{array}{l}\text { CHD pregnancies } \\
(n=467)\end{array}$ \\
\hline Functional status, n (\%) & $393(84)$ \\
I & $73(16)$ \\
III & $1(<0.5)$ \\
IV & $0(0)$ \\
Arrhythmias requiring a permanent pacemaker, & $1(<0.5)$ \\
n (\%) & $1(<0.5)$ \\
Severe mitral insufficiency &
\end{tabular}

Follow-up maternal cardiovascular outcomes for $467 \mathrm{CHD}$ pregnancies managed by the Programme 2000-2017

class II in nearly $16 \%(n=73)$ and class III in a further case $(<0.5 \%)$. Additionally, one patient $(<0.5 \%)$ developed an arrhythmia requiring a permanent pacemaker and another developed a severe mitral insufficiency $(<0.5 \%)$.

\section{Discussion}

Overall, the study identified 467 pregnancies (464 singleton, 3 twin). The median age at pregnancy in the study population ( 25 years), is similar to that reported in studies of high-income countries (26-30 years) [4, 10, 23]. Some provinces in Cuba appear to be significantly overrepresented (e.g. Havana) compared to others (e.g. Santiago de Cuba), even when accounting for differences in population density (see Fig. 1). To some extent this can be explained by the dual function the Hospital "Ramon Gonzalez Coro" plays as both the national referral centre for the management of high-risk CHD pregnancies, and also the regional centre for lower risk CHD pregnancies. Nevertheless, the relatively low rate of cases seen in some Cuban provinces compared to others (particularly to the capital) could indicate that patients further afield are not being appropriately referred to the programme, may be unwilling to travel to the capital for monitoring, or are remaining undiagnosed and are therefore not being referred.

Regarding pregnancy outcomes, the live birth rate (99\%) is particularly encouraging, with neonatal mortality rates approximately four times lower than have been reported elsewhere for CHD pregnancies [10, 11]. However, it is important to note that the study population was mixed in the level of risk the pregnancies presented; a significant proportion of cases were classified as low-risk. Overall, $89 \%$ of our cohort were in the mWHO class I-II category, where pregnancy would be considered to pose either no risk or a small increased risk of maternal mortality, or moderate increase in mortality [10]; 97\% of women in our cohort had a NHYA functional score of I at the start of pregnancy. Whilst this reflects the ACHD survivor population that would be 


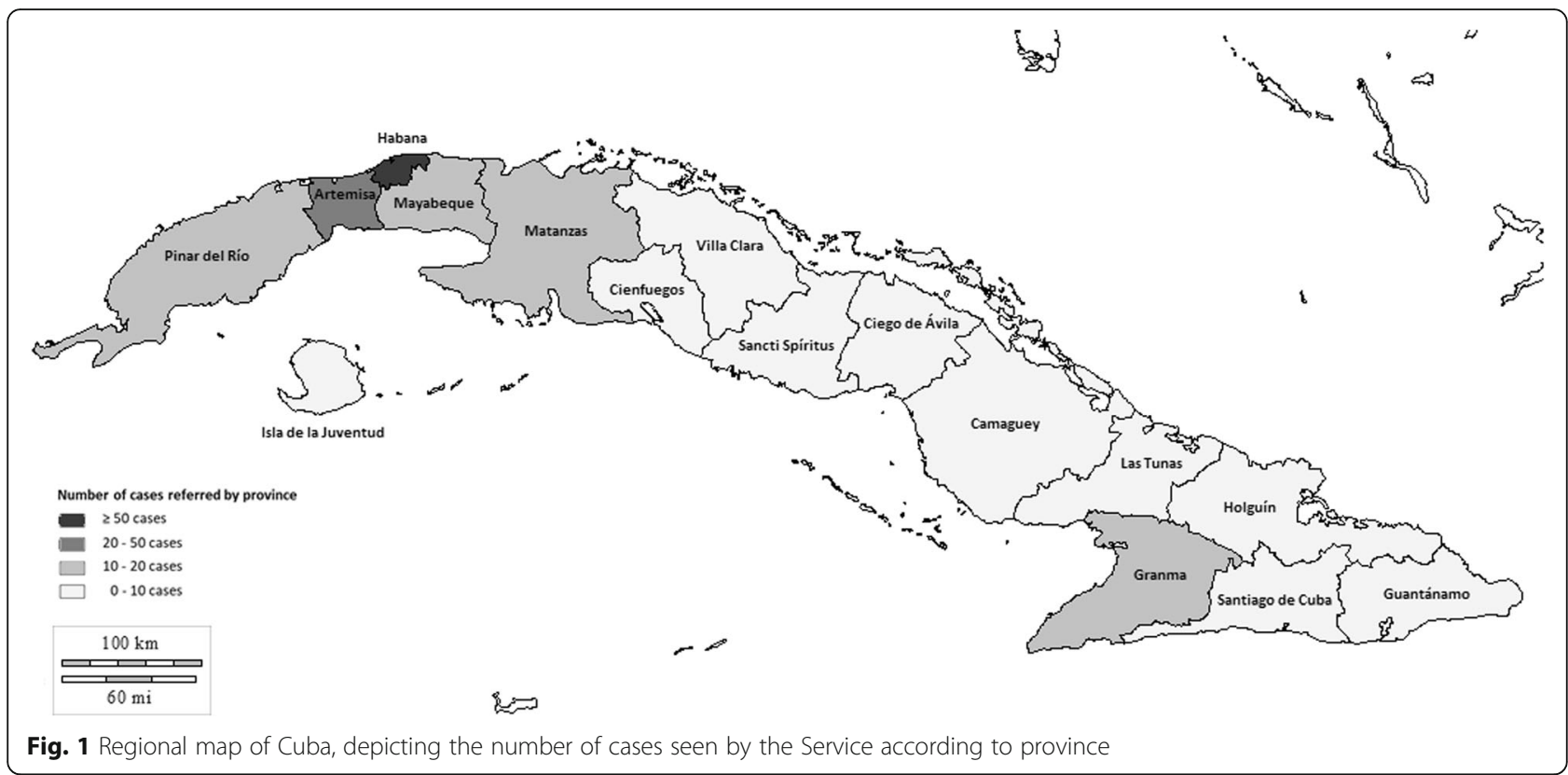

expected in a middle-income country, it also means live birth outcomes may not be entirely comparable to studies with a greater focus on high-risk CHD pregnancies. The caesarean rate reported for singleton pregnancies (34\%) is broadly similar to the rates reported in the literature [4], and lower than the national rate of caesarean sections of $40 \%$ in Cuba [24]. The 19\% rate of caesarean section rate for cardiac indications may seem high given that the majority of women were mWHOI and II, and could be a reflection of clinician anxiety regarding maternal wellbeing. In Cuba, a previous caesarean section would be an indication for a further caesarean in all subsequent pregnancies, differing from the practice of most Western countries, where vaginal birth after caesarean (VBAC) is now encouraged [25].

Rates of maternal cardiovascular complications are in line with those reported by Drenthen et al [4], but lower than most other studies $[9,11,16]$. Obstetric complications are generally lower than reported elsewhere [4], though rates of gestational diabetes were higher than the general Cuban population ( $8 \%$ vs $5.8 \%$ respectively) [26]. Lastly, neonatal adverse outcomes were also consistently lower than reported by others $[10,11]$. Rates of neonatal CHD were relatively low [3].

At follow-up, maternal cardiac functional status had decreased in $13 \%$ of the cohort. However, given the short-follow up time post-delivery ( 6 weeks), one must consider the context in which this outcome was measured; the decline in functional status could well be due to non-cardiac reasons, e.g. the normal fatigue experienced when looking after a new-born. It is therefore not possible to establish the long-term effects pregnancy and delivery have had on maternal cardiac function.

\section{Strengths and limitations of the study}

This work represents the largest report to date of a cohort of women, with 467 women with congenital cardiac disease who embarked on pregnancy in Cuba. Moreover, we have presented data from a middle-income healthcare system as few comparable reports exist in the literature [20-22]. However, owing to the study methodology, it was not possible to reconcile patient data for patients that had a subsequent pregnancy. As such, the analysis was based on individual pregnancy cases managed by the Service as opposed to outcomes based on inter-pregnancy dependent variables. The implications of this are mainly that we have underestimated the deterioration in cardiovascular function with subsequent pregnancies. For example, a woman could have experienced a deterioration in cardiovascular function in her 1st pregnancy, which further decreased in a subsequent pregnancy. However, given that most women had an NYHA score of I at the start of pregnancy, this is unlikely to be the case. Improvements in data linkage systems would enable more precise estimations of the impact of pregnancy on cardiovascular disease and vice versa. The short follow-up time and retrospective nature of the study also restrict the conclusions that can be made, particularly on long-term maternal cardiovascular outcomes following pregnancy for CHD patients.

\section{Conclusion}

Pregnancy and labour can cause a significant burden to the abnormal cardiovascular system. In the context of CHD, appropriate risk-stratification measures and clear management strategies developed within a multidisciplinary team remain critical for positive outcomes in both 
mother and child. The results of this study serve to demonstrate how, despite resource constraints, CHD patients can be successfully managed in middle-income countries at similar levels to those in more high-income healthcare systems. Nevertheless, the long-term outcomes of pregnancy remain to be established, and present a further avenue of research both in the developed and developing world.

\section{Acknowledgements}

We are grateful to the women who participated in the study.

\section{Funding}

CK was funded by a charitable grant from the Madeleine Steel Charitable Trust to undertake the work. We have no financial interests to declare.

\section{Availability of data and materials}

The datasets generated and/or analysed during the current study can be requested from the authors on reasonable request.

\section{Authors' contributions}

JP and PR designed the study and gained institutional approval. RV, JP and PR performed the data collection. CK processed the results and wrote the manuscript. ST, HC, PC, JP and PR reviewed the manuscript. All authors approved the final version prior to submission.

\section{Competing interest}

The authors declare that they have no competing interests.

\section{Ethics approval and consent to participate}

The research protocol was approved by the local Institutional Review Board. Verbal informed consent was obtained for all participants in the study; written informed consent was not deemed necessary by the Review Board.

\section{Consent for publication}

Not applicable.

\section{Publisher's Note}

Springer Nature remains neutral with regard to jurisdictional claims in published maps and institutional affiliations.

\section{Author details}

${ }^{1}$ Institute of Cardiovascular Sciences, Birmingham B15 2TT, UK. ${ }^{2}$ Department of Adult Congenital Cardiology, Queen Elizabeth Hospital Birmingham, Birmingham B15 2TH, UK. 'Birmingham Women's Hospital, Academic Unit, 3rd Floor, Metchley Park Road, Birmingham B15 2TG, UK. ${ }^{4}$ Department of Pregnancy and Heart Disease, Institute of Cardiology and Cardiovascular Surgery, 10400 Havana, Cuba.

Received: 10 January 2019 Accepted: 5 April 2019

Published online: 27 April 2019

\section{References}

1. Khairy P, lonescu-Ittu R, Mackie AS, Abrahamowicz M, Pilote L, Marelli AJ. Changing mortality in congenital heart disease. J Am Coll Cardiol. 2010; 56(14):1149-57.

2. Siu SC, Colman JM. Heart disease and pregnancy. Heart. 2001;85(6):710-5.

3. Roos-Hesselink JW, Ruys TP, Stein Jl, et al. Outcome of pregnancy in patients with structural or ischaemic heart disease: results of a registry of the European Society of Cardiology. Eur Heart J. 2012;34(9):657-65.

4. Drenthen $W$, Boersma $E$, Balci A, et al. Predictors of pregnancy complications in women with congenital heart disease. Eur Heart J. 2010; 31(17):2124-32.

5. Warnes CA, Williams RG, Bashore TM, et al. ACC/AHA 2008 guidelines for the Management of Adults with Congenital Heart Disease: executive summary: a report of the American College of Cardiology/American Heart Association task force on practice guidelines (writing committee to develop guidelines for the Management of Adults with Congenital Heart Disease): developed in collaboration with the American Society of Echocardiography, Heart Rhythm Society, International Society for Adult Congenital Heart Disease, Society for Cardiovascular Angiography and Interventions, and Society of Thoracic Surgeons. Circulation. 2008;118(23):2395-451.

6. Regitz-Zagrosek V, Blomstrom Lundqvist C, Borghi C, et al. ESC guidelines on the management of cardiovascular diseases during pregnancy: the task force on the Management of Cardiovascular Diseases during pregnancy of the European Society of Cardiology (ESC). Eur Heart J. 2011;32(24):3147-97.

7. Viñas Oliva R, Sanchez Ramirez N, Roman Rubio P, Reina Gomez G, Oliva J. Perinatal results of the heart disease in pregnancy Service of the Hospital of gynecology and obstetrics "Ramon Gonzalez Coro" in the biennium 20002001, Havana. Brasilian J Matern Paediatr Health. 2003;3(1):49-60.

8. Chio Naranjo I, Guerra Chang E, Yanes Calderon M, Roman Rubio P, Perez Torga JE, Perez Felpeto R. Repercusions of pregnancy in women with congenital heart disease. Cuban J Obstet Gynecol. 2012;38(2):170-81.

9. Siu SC, Sermer M, Colman JM, et al. Prospective multicenter study of pregnancy outcomes in women with heart disease. Circulation. 2001; 104(5):515-21.

10. Balci A, Sollie-Szarynska KM. Van der Bijl, et al. prospective validation and assessment of cardiovascular and offspring risk models for pregnant women with congenital heart disease. Heart. 2014;100:1373-81.

11. Drenthen W, Pieper PG, Roos-Hesselink JW, et al. Outcome of pregnancy in women with congenital heart disease: a literature review. J Am Coll Cardiol. 2007:49(24):2303-11.

12. Lindley KJ, Conner SN, Cahill AG. Adult congenital heart disease in pregnancy. Obstet Gynecol Surv. 2015;70(6):397-407.

13. Karamermer $Y$, Roos-Hesselink JW. Pregnancy and adult congenital heart disease. Expert Rev Cardiovasc Ther. 2007;5(5):859-69.

14. Whittemore R, Hobbins JC, Engle MA. Pregnancy and its outcome in women with and without surgical treatment of congenital heart disease. Am J Cardiol. 1982;50(3):641-51.

15. Presbitero P, Somerville J, Stone S, Aruta E, Spiegelhalter D, Rabajoli F. Pregnancy in cyanotic congenital heart disease. Outcome of mother and fetus. Circulation. 1994;89(6):2673-6.

16. Khairy P, Ouyang DW, Fernandes SM, Lee-Parritz A, Economy KE, Landzberg MJ. Pregnancy outcomes in women with congenital heart disease. Circulation. 2006:113(4):517-24.

17. Ouyang DW, Khairy P, Fernandes SM, Landzberg MJ, Economy KE. Obstetric outcomes in pregnant women with congenital heart disease. Int J Cardiol. 2010;144(2):195-9.

18. Thorne S, MacGregor A, Nelson-Piercy C. Risks of contraception and pregnancy in heart disease. Heart. 2006;92(10):1520-5.

19. Warnes CA. Pregnancy and delivery in women with congenital heart disease. Circ J. 2015:79(7):1416-21.

20. Cadena-Estrada JC, Colex MLT. Cardiovascular and perinatal characteristics of pregnant women with acquired or congenital heart disease, and of the newborn. Mex J Cardiol Nurs. 2013;21(3):94-102.

21. Avila WS, Rossi EG, Ramires JAF, et al. Pregnancy in patients with heart disease: experience with 1,000 cases. Clin Cardiol. 2003;26(3):135-42.

22. Casanova R, Selman-Houssein E, Palenzuela H, et al. Cuba's national pediatric cardiology program. MEDICC Rev. 2010;12(2):6-9.

23. Kaemmerer $\mathrm{H}$, Bauer $\mathrm{U}$, Stein J, et al. Pregnancy in congenital cardiac disease: an increasing challenge for cardiologists and obstetricians-a prospective multicenter study. Clin Res Cardiol. 2003;92(1):16-23.

24. UNICEF. Country profiles: Cuba. [Internet] Available from: https://data.unicef. org/country/cub/. [Accessed 24 ${ }^{\text {th }}$ March 2019].

25. Norman JE, Stock SJ. Birth options after a caesarean section. BMJ. 2018; 360:j5737.

26. Cruz-Hernandez J, Hernandez-Garcia P, Lang-Prieto J, Yanes-Quesada M, Iglesias-Marichal I, Marquez-Guillen A. Controversies in screening and diagnosis of gestational diabetes: Cuba's position. MEDICC review. 2016;18:35-9. 